\title{
La generación de mecanismos de participación política y el papel de la publicidad política en los países miembro de la Alianza Pacífico
}

\author{
Alma R. SALDiERna SALAS* \\ FELIPE DE JESÚS MARAÑón LAZCANO** \\ José Fredman MENDOZa IbARRA**
}

Archivo recibido: 16 de mayo de 2016

Archivo aprobado: 16 de diciembre de 2016

Doi: http://10.12804/revistas.urosario.edu.co/desafios/a.4873

Para citar este artículo: Saldierna Salas, A. R., Marañón Lazcano, F.J., \& Mendoza Ibarra, J.F. (2017). La generación de mecanismos de participación política y el papel de la publicidad política en los países miembro de la Alianza Pacífico. Desafios, 29(1), 79-106. Doi: http://10.12804/revistas.urosario.edu.co/desafios/a.4873

\footnotetext{
* Doctora en filosofía con Acentuación en Ciencias Políticas, UANL. Investigadora Asociada al Laboratorio de Comunicación Política (LACOP). Miembro del Sistema Nacional de Investigadores, nivel Candidato. Líneas de investigación: Actitudes y comportamiento político y Formación cívica. Correo electrónico: alma.saldiernas@uanl.mx. ORCID: http:// orcid.org/0000-0003-1805-9740

** Doctor en filosofía con Acentuación en Ciencias Políticas, UANL. Investigador Asociado al Laboratorio de Comunicación Política (LACOP). Miembro del Sistema Nacional de Investigadores, nivel Candidato. Sus líneas de investigación son Marketing político, Comunicación política y Estereotipos. Correo electrónico: felipe.maranonl@uanl.mx. ORCID: http://orcid.org/0000-0002-0705-6336.

*** Maestro en Ciencias Políticas por la Universidad Autónoma de Nuevo León (UANL) y actualmente Doctorando en Filosofía con Orientación en Ciencias Políticas por la misma Universidad (UANL). Becario CONACYT. Sus principales líneas de investigación son Participación política indígena, Movimientos sociales y acción colectiva. Correo electrónico: josefredman@hotmail.com. ORCID: http://orcid.org/0000-0001-7071-6045
} 


\title{
Resumen
}

La evidencia histórica demuestra que América Latina ha padecido desigualdad económica y politica desde siempre. Por eso, para disminuir estas problemáticas en la región, son fundamentales las uniones comerciales entre los países que hacen parte de ella. En ese sentido, la Alianza Pacífico surgió como un acuerdo para lograr el balance de las diferencias existentes entre los paises miembros y el desarrollo económico regional, teniendo como países fundadores a Chile, Colombia, Perú y México. Evidentemente, esto no se puede lograr sin considerar la situación política de cada uno de los países miembros, dado que necesitan fortalecer las politicas nacionales y consolidar las instituciones democráticas propiciando la participación política de sus ciudadanos; asi como otorgar los mecanismos apropiados para una democracia que conduzca a la prosperidad. El objetivo del articulo es resaltar los elementos teóricos que son necesarios para promover la participación politica ciudadana con el fin de lograr una democracia sana para el desarrollo y crecimiento económico regional. Por lo tanto, se analizarán los marcos regulatorios de cada país miembro de la Alianza Pacifico, y el papel de la publicidad política como herramienta de divulgación necesaria para la política en la construcción de la democracia.

Palabras clave: Consolidación democrática, desarrollo económico, participación política, publicidad política, Alianza Pacífico.

\section{The Generation of Political Participation Mechanisms and the Role of Political Advertising in the Member-Countries of the Pacific Alliance}

\begin{abstract}
Historical evidence shows that Latin America has always suffered from economic and political inequality where the role of commercial unions is fundamental in order to eliminate such barriers. In this sense, the Pacific Alliance has emerged as an agreement to balance the existing differences between its member-countries and to achieve regional economic development. Evidently this cannot be achieved without considering the political situation of each one of its members and how national policies should be enforced besides consolidating the democratic institutions by stimulating the political participation of citizens and generating the appropriate mechanisms given that
\end{abstract}


democracy leads to prosperity. The objective of this article is to bighlight the theoretical elements that are needed for the motivation of citizen's political participation in order to seek a healthy democracy for the development and growth of regional economies. This objective is achieved by analyzing the regulatory frameworks of each of the Pacific Alliance's member-countries and the role of political advertising as a dissemination tool for the construction of democracy.

Keywords: Democratic consolidation, economic development, politicalparticipation, political advertising, Pacific Alliance.

\title{
A geração de mecanismos de participação política e o rol da publicidade política nos países membro da Aliança Pacífico
}

\begin{abstract}
Resumo
A evidência histórica demonstra que a América Latina tem padecido desde sempre desigualdade económica e política, onde o rol das uniões comerciais é fundamental para eliminar barreiras. Neste sentido, surge a Aliança Pacifico como acordo para conseguir o balanço das diferenças existentes entre os paises membro e o desenvolvimento económico regional, tendo como países fundadores ao Chile, à Colômbia, ao Peru e ao México. Evidentemente, o anterior não pode conseguir-se sem deixar de lado a situação política de cada um dos países membro, pois precisam-se fortalecer as políticas nacionais e consolidar às instituições democráticas propiciando a participação política dos seus cidadãos; assim como outorgar os mecanismos necessários na procura de uma democracia sana para a geração de prosperidade nas sociedades. $O$ objetivo do artigo consiste em aportar elementos que permitam analisar, desde uma perspectiva teórica, a importância e a relevância de empreender ações que motivem a participação política dos cidadãos na procura de uma democracia sana para o desenvolvimento e crescimento económico regional. Portanto, se analisaram os marcos regulatórios de cada país membro da Aliança Pacifico, assim como também o rol da publicidade política como ferramenta de divulgação necessária para a política na construção da democracia.
\end{abstract}

Palavras-chave: Consolidação democrática, desenvolvimento económico, participação política, publicidade política, Aliança Pacífico. 


\section{Introducción}

A través de los cambios semánticos en términos como democracia, economía, Estado, derechos humanos y desarrollo suscitados al paso del tiempo, éstos han adquirido particular relevancia en América Latina. A guisa de enarbolar teoréticamente el hilo conductor del presente artículo, en los siguientes parágrafos se esbozará lo que se entiende por democracia en forma general, para después explorar la relación que existe entre la consolidación democrática y el desarrollo económico dentro del plexo constituyente de la Alianza Pacífico, y sus repercusiones en la teorización de la democracia en América Latina.

Para tal empresa se tornará ineluctable dar cuenta de los albores de la democracia en las sociedades políticas occidentales. Por un lado se establece que, a raíz de dos transformaciones en la vida política del ser humano, la noción moderna de la democracia, así como sus prácticas e instituciones, adquirió relevancia y pretensión universal de validez, es decir, en un primer momento de tal transformación, el punto nodal se configuraba en torno a las "ideas y prácticas democráticas y republicanas en la ciudad-Estado" (Dahl, 1992, p. 257) que giraban en sociedades "pequeñas" o con un número muy reducido de integrantes y a lo sumo solo en un contexto europeo; por otro lado, y con la aparición del Estado-nación (país o Estado nacional), la idea de la democracia abrazó a una gran sección de países del planeta tanto en términos ideológicos como de aspiración política.

Por mor del tamaño de los integrantes en el Estado-nación, el elemento democrático de representación adquirió relevancia en demasía por ser un "fenómeno histórico y a la vez una aplicación de la lógica de la igualdad a un sistema político de gran tamaño" (Dahl, 1992, p. 259), además del nacimiento de las instituciones, los límites a la participación directa, la expansión de derechos individuales y el pluralismo social. Según Bobbio (1986), la democracia es "un conjunto de reglas procesales para la toma de decisiones colectivas en el que está prevista y propiciada la más amplia participación posible de los interesados" (p. 9) , mientras Bovero (2002) sugiere una serie de 
verbos: elegir, representar, deliberar, decidir y tejer para marcar las "reglas del juego" para la democracia.

No obstante, y ya entrado el siglo XXI, confluir la noción de la democracia -en términos de competencia de intereses y a través de algunas reglas del juego- con el desarrollo político, económico y social de un Estado-nación, reverbera un quiebre ontológico, pues "una interpretación exclusivamente política, atada a la lógica de toma de decisiones y de representación de intereses, no puede dar cuenta de las transformaciones de producción social y de la modificación de necesidades e intereses sociales" (Melucci, 2010, p. 170). En ese sentido, el punto de partida es un Estado-nación que se ve inmiscuido en relaciones transnacionales y con un sistema interdependiente, que desdibuja la carátula del Estado como el único agente tanto de coacción legítima (Hardt \& Negri, 2005) como de toma de decisiones, pero que, a su vez, se torna imprescindible para la producción y reproducción de pautas económicas, políticas y sociales, que tienen la opción de despuntar 1) hacia la reproducción capitalista, o 2) hacia la reproducción de igualdades sociales que trasciendan libertades de corte instrumental para erguirse en igualdades sociales en términos de libertades sustantivas (Osorio, 2014).

\section{Democracia y Desarrollo económico}

A guisa de esclarecer semejante dialéctica del Estado-nación descrita en el párrafo anterior, es perentorio esquematizar cómo y a partir de qué la teorización de la democracia en un contexto latinoamericano ayudará a constituir el progreso y desarrollo de la región. En primer lugar, históricamente América Latina se ha construido a partir de la negación de la negación en un sentido propiamente marxista, es decir, la acumulación originaria constituyente de la economía política (mundial para unos, eurocéntrica para otros) supuso despojos en la región latinoamericana desde el siglo XVI y que en la historia real se reconoce que "desempeñan un gran papel la conquista, la esclavitud, el robo y el asesinato; la violencia, en una palabra" (Marx, 1991, p. 607) para la acumulación originaria. En ese sentido, América Latina desde 
tiempos primigenios ha padecido considerables sintomas de desigualdad ecónomico-politicos a partir de la variable étnica-cultural (Galeano, 2015).

Por esta razón, se torna acuciante dar cuenta de que la democracia como sustento del Estado ${ }^{1}$, refleja al menos dos tipos de operacionalización: 1) el paradigma 'agregativo' (Mouffe, 2011), que supone una racionalidad instrumental y toma por basamento el individualismo, alimentando el problema de la exclusión; y 2) el modelo 'deliberativo', que supone una racionalidad comunicativa (Habermas, 2014) y abraza la idea de un diálogo igualitario, aunque en su versión negativa, el puede reproducir una hegemonía que sustente exclusiones y barbaries inimaginables, pero reales, tal como sucede en el modelo agregativo. Por ello, se ha de dictar dos premisas: si el Estado es el ente estructural que podrá basarse en la democracia para el establecimiento de la vida misma dentro de ciertos límites territoriales, ${ }^{2}$ la democracia podrá aparecer en su aspecto procedimental o sustantivo ${ }^{3}$ (Osorio, 2014).

En segundo lugar, la democracia en términos sustantivos podrá tornase dable cuando la inclusión del otro sea fundamental para su construcción. El respeto de los derechos humanos, así como la participación política de las minorías étnicas y la consolidación -positiva- del fenómeno migratorio, representará el acicate que encauzará el desarrollo políticosocial al sendero del progreso económico. Es tal el desafío que conlleva la praxis de una democracia sustantiva, que la construcción de una narrativa que haga suya la idea de que la totalización del yo no es posible no por la insuficiencia o incapacidad

\footnotetext{
1 Para fines del presente artículo aparecerá como Estado Liberal.

2 Es preciso señalar que en el siglo XXI tales límites podrán desdibujarse por el aspecto regional, transnacional, identitario/cultural y de interdependencia económica.

3 Aunque en las dos reina el imperativo categórico de la igualdad, en la primera de ellas el aspecto jurídico-institucional de la competencia en elecciones y entre partidos (igualdad en tanto una cabeza un voto) prima sobre lo sustantivo, pues este último reconoce la insuficiencia de los mecanismos instrumentales de la democracia para la inclusión y el desarrollo económico real de la sociedad, pues no olvida que la igualdad en términos económicos dista de ser la idílica igualdad política electoral.
} 
de este, sino por la mera existencia del otro ${ }^{4}$ (Levinas, 2012), constituirá relaciones sociales que determinen la constitución del individuo mismo, al tiempo que repercutan en la estructura societal (Bartra, 2013; Horkheimer, 2008).

Llevando lo anterior a la arena política, La democracia requiere distinguir entre nosotros y ellos para hacer factible el reconocimiento del pluralismo, pues los hombres nacen iguales, y al tiempo, diferentes, y es ahí donde el poder constitutivo de la democracia moderna hace su aparición (Fromm, 1982; Mouffe, 2011). Por lo tanto, a partir de la consolidación de la democracia en su sentido sustantivo, Latinoamérica podrá iniciar la reconfiguración del desarrollo económico en la región, para ello, la noción y estructura de la democracia en términos participativos será imprescindible en la modulación de desarrollo económico. Es decir, la participación política, entendida como la "actividad necesaria para que el gobierno respete y proteja la libertad que permite a los individuos proseguir sus actividades y vincular sus vínculos personales" (Kymlicka \& Norman, 1997), será el punto axial que, junto con el papel que desempeña la publicidad política en cuanto al fortalecimiento de sistemas políticos, económicos y sociales como la Alianza Asia-Pacífico, permitirá el crecimiento tanto de los países miembros de la Alianza Pacífico como de la región en general.

Lejos de considerar como axioma nomotético aquella sentencia que dicta la historia en cuanto a que el crecimiento económico permite la mejora de las condiciones de vida, es necesario demostrar cómo es que tal empresa puede ser posible en una región como América Latina, en la que, dicho sea de paso, el saqueo y la violación de lo que ahora se reconoce como derechos humanos fueron prácticas constituyentes del continente (Reyes, Romero, De Onís, Baeza \& Arciniegas, 1977). Para ello, Piketty (2014) advierte que la convergencia entre países donde persiste la desigualdad les permitirá dejar de ser meras propiedades

\footnotetext{
4 Tal analogía en términos filosóficos responde a la necesidad de clarificar que por más libertades políticas y económicas, así como mecanismos jurídicos y de representación para la realización de la democracia, siempre la última palabra será la que disponga del respeto al otro: al indígena, al migrante, al pobre, a los que se les ha despojado de esperanza.
} 
de países más desarrollados a partir de la difusión de conocimiento tecnológico y educación, a través de la apertura comercial e internacional acompañada de procesos constructivos de legitimidad, eficiencia y confianza política. De tal manera que la promesa de una integración regional en términos culturales, económicos, políticos y sociales dependerá de la participación política de los ciudadanos, así como de la eficiencia de sus mecanismos de participación y de la difusión política de los mismos para la construcción de legitimidad. Todo ello solo podrá ser concebido si se tiene como basamento praxeológico ${ }^{5} \mathrm{y}$ ontológico $^{6}$ a la democracia sustantiva.

No obstante, se debe considerar los riesgos siempre latentes de la lógica económica en la sociedad; por un lado el aumento de la productividad económica supone condiciones más justas para la población en general y, por el otro lado, forja el cuidado y mantenimiento de una lógica técnica y a los grupos sociales-políticos que disponen de ella. Cabe destacar que éstos, en su forma negativa, suponen una superioridad sobre el resto de la población (Adorno, 2007).

Por lo tanto, resulta perentorio que para sopesar tales riesgos se lleve la argumentación a un nivel más concreto como los mecanismos de participación política y el papel de la publicidad política en cuanto a su injerencia en la consolidación democrática en el desarrollo económico de la región latinoamericana, en general, y en los países miembros de la Alianza Pacífico, en específico. Todo con la finalidad de regular los alcances del desarrollo económico y que la vida democrática de los ciudadanos sea posible en términos de dignidad y progreso humano.

\footnotetext{
5 Con referencia a la praxis de la democracia participativa como eje de la democracia sustantiva.

6 Tal categoría permite unir la esencia con la existencia: si la esencia del ser-ahí, siguiendo a Heidegger, radica en su existencia, necesariamente la existencia se tornará indispensable. Para efectos del artículo, el respeto a la existencia, es decir, a la vida, consolidará toda noción de derechos humanos.
} 


\section{El camino a la construcción de la democracia}

El principio democrático se centra en que las decisiones que afectan a la comunidad son tomadas por los ciudadanos (Silva-Herzog, 1999), para lo que debe existir libertad e igualdad política, así como instituciones estables y con legitimidad (Diamond \& Morlino, 2005). En ese sentido, Dahl (1999) considera que la democracia se presenta como el sistema político más aceptable, debido a que garantiza ventajas sobre otros sistemas políticos de gobierno por lo siguiente: a) evita la Tiranía; b) garantiza derechos esenciales; c) otorga libertad general; d) promueve la autodeterminación; e) proporciona autonomía moral; f) incentiva el desarrollo humano; g) protege los intereses personales esenciales; h) fomenta altos grados de igualdad política; i) produce la búsqueda de la paz y j) genera prosperidad en las sociedades. De ahí la importancia de la búsqueda de una estabilidad democrática y política en los países miembros de la Alianza Pacífico. En la medida en que internamente se cimienten los pilares de la consolidación de democracias sanas, se fomentará también el desarrollo integral de la región.

En este sentido, es necesario analizar las condiciones sociales y económicas de los países, así como también las instituciones políticas que existen en una sociedad democrática, pues en ese trasfondo se van a gestar las actitudes políticas que van a estar presentes en esa sociedad democrática y cuyo resultado cristalizará en una cultura política democrática regional. La propuesta de la Comisión Internacional sobre la educación del siglo XXI de la UNESCO, recalca la necesidad de formar una cultura ciudadana que vaya gestando en los individuos esa necesidad de participar activamente en el desarrollo de su sociedad, así como en la formación de actitudes y aptitudes que edifiquen una cultura política democrática (UNESCO, 1994).

\section{La participación política en la Alianza Pacífico}

La Alianza Pacífico surge en 2011 con el objetivo de generar un acuerdo comercial entre Chile, México, Colombia y Perú. Sin embargo, en la búsqueda del desarrollo económico regional, se puede evidenciar la existencia 
de diferencias significativas en temas económicos y problemas sociales y políticos. Por lo tanto, ¿qué papel juega la política en la realización del acuerdo comercial? El papel de la política es crucial, es necesario conocer su situación, analizar la forma de gobierno, los mecanismos de toma de decisiones y los niveles de acción de los ciudadanos (Bown, 2012). Estos son ejes rectores para el buen funcionamiento económico del acuerdo comercial que se vaya a realizar y las normas democráticas internas son cruciales para lograr la cooperación internacional.

De acuerdo con el Departamento de Asuntos Económicos y Sociales de la ONU (2012), es necesaria la cooperación entre las naciones, pero también es necesario fortalecer las políticas nacionales que promuevan el diálogo en beneficio de lograr un desarrollo económico justo y eficiente, para que sea posible aprovechar la generación de alianzas que permiten un crecimiento integral entre los países involucrados (Risse-Kappen, 1995). Generando así una estabilidad política y cambio positivo en lo económico y lo social Es decir, desde una perspectiva estatista, se ejemplifica al Estado-Nación; como aquel constituido por cultura, identidad, así como estabilidad política; además que es necesario democratizar a la sociedad para favorecer el bienestar económico (Bustamante \& Morandé, 2007). Autores como Grindle (2009) afirman que si no se considera el contexto económico, político y social, será imposible lograr objetivos exitosos en la integración de las regiones en términos económicos.

En ese sentido, el marco de la Alianza Pacífico dentro de sus cinco estrategias aborda el eje relacionado con la participación ciudadana. En aquél los analistas y políticos afirman que la participación ciudadana es un factor indispensable en la búsqueda de desarrollo y dinamismo de las economías de la región con lo cual tiene que ser un punto significativo a considerar junto con los derechos humanos, la gobernabilidad democrática y la libertad de expresión (Declaración Mérida, 2012). Un país que fomente la participación ciudadana tendrá legitimidad en su gobierno, buscará la conformación de una cultura democrática, al tiempo que hará más eficientes las decisiones políticas y la gestión pública (Ziccardi, 2004, p. 50). 
Debido a lo anterior, en el camino a la consolidación de la democracia se requiere de espacios y mecanismos que propicien la participación ciudadana al interior de cada país miembro (Martínez, 2009), diseñando su implementación y fortaleciendo las estructuras legales que propicien el involucramiento de los ciudadanos en la política (Moreno, 2004), ya que a través del fortalecimiento de la democracia a nivel nacional, el país contribuirá al desarrollo y crecimiento de la región.

\subsection{La participación política en Perú}

En las pasadas elecciones del 10 de abril de 2016 en el Perú, la lista nominal estaba conformada por 22'901.954 ciudadanos en posibilidad de ejercer su derecho a voto (JNE, 2016). Así mismo, el Padrón Electoral indica que el mayor porcentaje de votantes se encuentra en el rango de edad de 20 a 29 años con más de 6’900.000 que representan el 30,25 \% del padrón electoral. Estos datos demuestran por qué todos los mecanismos que promuevan la participación de los ciudadanos tienen que enfocarse en este segmento de la población. En ese sentido, en 2002 el 14,8 \% de los candidatos a los concejos locales eran jóvenes, lo que representaba un número muy bajo; así mismo los datos de preferencias y niveles de participación mostraban indicios de bajos niveles de participación política (INEI, 2010).

Con un segmento de votantes jóvenes tan amplio, éstos se convierten en un conjunto de actores estratégicos en los que es necesario enfocar todas las regulaciones necesarias para incentivar la participación política en la búsqueda de la legitimidad y consolidación de la democracia. Ello da origen a la Ley de Bases de la descentralización. La finalidad de esta ley es la creación de una estructuración organizada del Estado, descentralizando y desconcentrando al gobierno en sus tres niveles: nacional, regional y local, teniendo como objetivo el desarrollo del país (Ley de bases de la descentralización, 2001).

En referencia a la participación, se promueve que la información pública este libre a todos los ciudadanos, y se incentiva la creación de espacios en donde se puedan realizar consultas, así como también evaluación y rendición de cuentas. Esto tiene como finalidad incluir 
pesos y contrapesos para que los ciudadanos estén más involucrados en lo que sucede en la esfera política, económica y administrativa, incluyendo el diseño de políticas públicas en congruencia con los intereses de los ciudadanos (USAID Perú Pro-Descentralización, 2011). Tal acción permite el surgimiento de la ley de Concejal joven (Ley No. $28869,2006)$, con la que se busca incentivar la participación política de los jóvenes y se establece que los candidatos a elecciones municipales deben contar con no menos del $20 \%$ de jóvenes menores de 29 años. La finalidad es que toda la población se sienta incluida en los procesos de toma de decisión política, teniendo como consecuencia un incremento considerable en la participación política a través del voto y devolviendo de esa manera la confianza en las autoridades. Sin embargo, el camino para llegar a tal punto de democracia en Perú fue largo; anteriormente, se tuvo que pasar por la formulación de leyes previas que posibilitaran esto, como lo son la Ley de los Derechos de Participación y control de ciudadanos (Ley No. 26300, 1994), la Ley orgánica de gobiernos regionales (Ley No. 27867, 2002), la Ley orgánica de municipalidades (ley No. 27972, 2003), la Ley orgánica del poder ejecutivo (Ley No. 29158) y la Normatividad del servicio civil (DS No. 007-2010-PCM, 2010).

Con estas leyes no solo se busca que se active la participación política de los jóvenes, sino que se agrupen todos los sectores vulnerables a través de la inclusión y rendición de cuentas, con ello logrando el incremento de la confianza en las instituciones y por ende el incremento en la participación política. La evidencia empírica visibiliza la existencia de una correlación positiva entre el hecho de ir a votar como forma de influir en los procesos políticos y tener un sentimiento de eficacia política elevado (Moreno, 2012). Con ciudadanos involucrados en el sistema político, el índice de salud en los sistemas democráticos adquiere niveles prominentes y provechosos para todo sistema político (Sharoni, 2012).

El resultado que se tiene es que de acuerdo a la Encuesta de Participación Política (SENJU, 2011) el 60 \% de la población considera que la política se renovó, el $70 \%$ de las personas consideran que se incrementó el nivel de participación política sobre todo en los jóvenes. Con 
respecto a estos últimos, se encuentra que solo el 20\% afirmó que no participa por la desconfianza en las autoridades (si bien es un dato importante, realmente este no es muy elevado); así mismo un 10\% consideró que no participa porque existen demasiados requisitos que hacen que se limite su participación. Por otro lado, un dato a considerar es que un $50 \%$ de la población considera que no participa por falta de información. En ese sentido, es importante analizar los mecanismos de transmisión de información, sobre todo en política, que contribuya a la generación de un puente entre la esfera política y la esfera pública, esto es: en todos aquellos agentes de socialización política.

\subsection{Participación política en Colombia}

Colombia, como la mayoría de los países en América Latina, ha sufrido del clientelismo y el autoritarismo, obteniendo con ello falta de legitimidad en el sistema político y en las acciones gubernamentales que se evidenciaban con elevados niveles de abstencionismo por parte de la ciudadanía. Es en la época de los ochenta, cuando se promulga la Ley 11 de 1986, que incidió en la estructuración del sistema político colombiano. Ahora la población puede formar parte en la toma de decisiones y discusiones en la esfera política, la participación política se institucionalizó y se vio cristalizada con la expedición de la Carta Política en 1991, considerada como uno de los avances más importantes para la generación de participación política en Colombia (Velázquez \& González, 2003).

El caso colombiano proporciona una serie de regulaciones a su marco jurídico para poder establecer las reglas de la relación que se da entre las autoridades públicas y los ciudadanos; además, se establece un ambiente donde estos tienen acceso a la información referente a propuestas, libertad de opinar sobre los temas públicos, además de incentivar la rendición de cuentas. En el artículo 40 de la Constitución Política Colombiana se establece que todos los ciudadanos además de tener la posibilidad de votar, y ser votados, también tienen el derecho a participar en consultas populares, plebiscitos, movimientos y agrupaciones políticas sin limitar la libertad de pensamiento. El Estado debe ayudar en la organización, capacitación y promoción de esas 
agrupaciones, quedando esto fundamentado en el artículo 103 de la Constitución Colombiana (Constitución Política de Colombia, 1991).

Así mismo, existe la Ley 134 (1994), que tiene todas las normas y reglamentaciones para los mecanismos de participación en Colombia. En ella se detalla, de manera clara, cada uno de los derechos y prohibiciones a la hora de que los civiles se organizan cuando hay consultas populares, plebiscitos, etc. Es importante recalcar el papel del Sistema Nacional de Planeación, así como los consejos nacionales y territoriales de planeación que facilita el ejercicio de la participación política en todas las regiones del país.

Las acciones emprendidas por el gobierno han generado que, de acuerdo a la Encuesta de Cultura Política (DANE, 2013), el 73.9\% conozca o haya conocido algún mecanismo de participación ciudadana, lo que indica el nivel de conocimiento sobre la forma en que los ciudadanos pueden involucrarse en política. Algo preocupante es que tal valor se ve reducido en la encuesta de 2015, al pasar a un 58.6\% (DANE, 2015). En 2013 el mecanismo que más conocían era el Referendo con un 58. 9\% y pasó a un 52.3\% en 2015.

En 2013, el 86,1\% de los colombianos consideraba que una de las características de la democracia es la posibilidad que tienen todos de participar. Sin embargo, el 34,1\% de los colombianos se sentía insatisfecho con la democracia en el país, así como también el 50,1\% no confiaba en los partidos políticos.

En el tema de participación política relacionada al voto se puso en evidencia que el 53,9\% de la población siempre votaba, pero el 35\% no cría en el proceso electoral y al 47,9\% no le interesa la política; tal vez esto sea el reflejo de la falta de confianza en sus instituciones y en sus gobernantes. El 43,7\% considera que los candidatos prometen y no cumplen, así como el 43,3\% considera que la política es corrupta (DANE, 2013).

Por otro lado, en 2015 se encontró que el 28.9\% considera al país como democrático, el 56\% no confía en los partidos políticos, el 26,5\% 
considera que las votaciones son transparentes, pero algo importante a recalcar es que, a pesar de esa desafección sobre la democracia y los procesos políticos, los colombianos consideran que votar es importante y que es un derecho y un deber como ciudadano, pues el 82,4\% lo afirmó así (DANE, 2015).

Si bien el Estado se ha encargado de cimentar y difundir los mecanismos de participación como eje central para la legitimación y consolidación de la democracia Colombiana, es necesario seguir en el camino de inclusión de todos los colectivos. Sobre todo, se deberá seguir en el proceso de información para que la ciudadanía no caiga en la desinformación de cómo participar, así como también trabajar en lograr la confianza en los partidos políticos.

\subsection{Participación Política Chile}

El contexto de Chile está inmerso en grandes problemáticas. Si bien está en el proceso de avanzar a pasos agigantados, también es evidente que existe una gran desigualdad socioeconómica (Fuentes \& Villar, 2005).

La historia chilena tiene en sus memorias una alta intervención del poder ejecutivo en los procesos electorales en el siglo XIX, que culmina con un golpe de Estado en 1973. En la vida política del país es imposible dejar de hablar de los movimientos sociales, pues éstos propiciaron un gran cambio a la estructura electoral en las elecciones de 1920. El inicio de la dictadura en 1973 y su fin en 1988 estuvieron marcados por el mecanismo de participación política de los ciudadanos: el plebiscito y la convocatoria a elecciones en 1989 (Biblioteca Nacional Digital, 2015). En 2011 se creó la Ley 20.500, que hace referencia las asociaciones y participación ciudadana y gestión pública, teniendo como eje el asentar el marco legal para promover la participación ciudadana en el país. Esta ley establece el derecho, limitaciones y papel del Estado en relación con las asociaciones, así como también favorecer que los ciudadanos participen en temas de política pública (Ley 18.575; Ley 18.695). Finalmente, se aprueba la Ley 20.568 en 2012 , en donde se aborda el tema del voto, promo- 
viendo el sufragio universal logrando la adscripción de 4’500,000 nuevos electores.

Otra acción emprendida es la implementación del Instructivo Presidencial sobre participación ciudadana, que busca el fortalecimiento de la sociedad civil con la creación de consejos de la sociedad civil para ser el enlace más cercano con la población y, de esa manera, involucrar las demandas e inquietudes en todo proceso de toma de decisiones y diseño de política pública (Secretaría General de Gobierno, 2015); además, se complementa con una Política para la participación ciudadana en el marco de la corresponsabilidad, teniendo como ejes centrales, la información y consulta ciudadana, el control ciudadano y el fortalecimiento de la sociedad civil, todo esto con la finalidad de mejorar los canales y espacios de información de la ciudadanía (Secretaría General de Gobierno, 2011).

Este marco legal implementado buscaba reducir los problemas de participación política en el país. En 2005, el 85\% de las personas de 29 años no estaba inscrito para votar (Fuentes \& Villar, 2005). En las elecciones de 2014 había una población de jóvenes de 342.267, de los cuales solo 176.132 solicitaron el DIU (Documento de identidad), lo que representa solo el $51.46 \%$, y demuestra la falta de interés en involucrarse en este proceso democrático.

Estudios evidencian que solo el 44\% votó en las elecciones de 2012, y que es la población que menos participa en América Latina. Además de las regulaciones, se han creado compañas dentro del Instituto Nacional de la Juventud (INJUV, 2010), como lo es el programa llamado "yo voto" en el que a través de herramientas como el internet los jóvenes tienen conocimiento sobre lo que sucede en el entorno político electoral y vean la necesidad de involucrarse en la política. Por su parte el centro de estudio públicos (CEP, 2014) encuentra que el $53 \%$ de los encuestados no está interesado en la política, un 50\% no se identifica con ninguna coalición política y un $57 \%$ no sigue ninguna tendencia política. Todo lo anterior pone en evidencia la crisis de los mecanismos de participación, el desinterés y la desconfianza en la política. La Auditoria a la Democracia del PNUD (2014) afirmó que 
todavía no son eficientes las herramientas que utiliza el Estado para lograr incentivar a los ciudadanos a involucrarse en la vida pública; por lo tanto, es necesaria la revaloración del actuar del Estado en su relación con los ciudadanos para hacer más eficiente su relación en la búsqueda de una estabilidad social, económica y política.

\subsection{Participación Política en México}

En México, de acuerdo con la Constitución Política Mexicana en su Capítulo IV, artículo 34, el estatus de ciudadano se obtiene al cumplir la mayoría de edad, lo cual confiere al nuevo ciudadano el derecho y la obligación del voto, aunque no exista sanción alguna si este no se emite. Ello puede llevar a la idea de que la participación de sus ciudadanos se produce por medio de las elecciones, aunque la realidad es diferente. En otras fracciones del artículo, se hace referencia a que los ciudadanos pueden asociarse libremente asociarse y de manera pacífica para deliberar y hacer frente a diversos asuntos políticos, abriendo por tanto otros mecanismos de participación de la ciudadanía más allá del tradicional voto.

En materia electoral, es en 1977 cuando se permite la inclusión de otros partidos políticos al sistema abriendo el camino a la participación política institucional. Posteriormente, en 1990, las elecciones se desarrollaran de manera limpia y es cuando surge el Instituto Federal Electoral con acciones necesarias y acordes al modelo económico neoliberal que comenzaba a imperar en el país (García, 2000).

Entre 1996, con Ernesto Zedillo a la cabeza del ejecutivo, se permite que los ciudadanos participen en la gestión de los comicios, apoyando al Instituto Federal Electoral (1997), además de implementar en los municipios los 'martes ciudadanos', en los que se ofrecen audiencias públicas para entablar una relación más cercana entre el Estado y los ciudadanos (Serrano, 2015). En ese sentido, comienzan a surgir mecanismos en algunos estados de la República Mexicana, que buscan reactivar la participación ciudadana a través de la Ley de Participación Ciudadana, que para 2012 ya había sido aprobada en 18 estados del país. 
Por otro lado, surge la Ley del fomento a las actividades realizadas por organizaciones de la sociedad civil, que básicamente está enfocada en regular las organizaciones de participación civil. Tal Ley reglamenta la organización de asociaciones relacionadas a actividades cívicas, como, por ejemplo, proporcionar apoyo alimentario a sectores populares para dar asistencia jurídica. Por último, la Ley federal de transparencia y acceso a la información política gubernamental incentiva a la participación con base en el acceso a toda aquella información que permita cuestionar el buen desempeño de las autoridades políticas, así como el buen uso de los recursos públicos, facilitando con ello la rendición de cuentas.

Tales acciones no han contribuido del todo a favorecer el incremento en los niveles de participación política. De acuerdo con datos de la Encuesta Nacional sobre Cultura Política (ENCUP, 2012), ocho de cada diez ciudadanos perciben la política como un tema complicado, tienen confianza institucional en la Iglesia, maestros, Militares y Televisión, mientras que desconfían en instituciones como Sindicatos, diputados, Senadores, es decir, instituciones primarias. Ello invita a recordar que tal fenómeno no existe en una democracia consolidada. Otro dato importante a recalcar es que $65 \%$ de los entrevistados declararon tener poco interés en la política, dato que aumentó con respecto a la encuesta anterior. Además ocho de cada diez mexicanos solo ven el voto como un mecanismo de participación política, y cuatro de cada 1 diez consideran que no pueden influir en las decisiones de gobierno, resultado que se encuentra por debajo de la media (ENCUP, 2012).

De igual manera, la Encuesta Nacional de Valores 2012 (IMJ, 2012), realizada por el Instituto de la Juventud de México, pone en evidencia la falta de interés de los jóvenes por la política; ello debido a que el 89.6\% de los encuestados no están interesados en la política del país y reprueba a los partidos políticos y a los funcionarios. Por su parte, el Colegio de México (COLMEX, 2012) informa en una encuesta realizada a 3.250 jóvenes entre 18 y 29 años, que el 32\% no cuenta con alguna ideología. Por otro lado, con respecto a su participación política, el $86 \%$ considera que el voto es poco o nada efectivo para 
presionar a las autoridades. Además, en relación a su participación ciudadana, entre el 90 y 97\% jamás ha formado parte de organizaciones culturales, estudiantiles, deportivas, religiosas, de partidos políticos o sindicatos (Gómez \& Aguilar, 2013).

México tiene trabajo democrático por realizar, pues como todo régimen democrático tiene la obligación de formar conciencia cívica en los ciudadanos, ser dinámico y promover las interrelaciones y el diálogo para fortalecer y perfeccionar la democracia del país (Salazar, 1990).

Por otra parte, la sociedad del siglo XXI ha estado marcada por diversos aspectos políticos, económicos sociales y sobre todo tecnológicos, que han influido en la globalización y el proceso de la democratización. El papel de la innovación en la forma de comunicarse, transmitir la información y transparentar las acciones de gobierno ha sido transcendental; estas nuevas herramientas permiten el surgimiento de lo que Castells define como "un lenguaje digital universal" (2004, p. 31). El lenguaje ha cambiado en la vida diaria, la forma en que se percibe la realidad y en cómo se evalúa la incertidumbre y el riesgo (Castells, 1996), abarcando, con ello, la forma de relacionarse en la política. Los medios de comunicación son el puente perfecto entre el Estado y los ciudadanos (Abundis, 2007), fomentan la producción y distribución de palabras así como también transforman las identidades y temperamentos de los individuos. Es relevante analizar el papel que juegan los medios de comunicación en el proceso de consolidación democrática a la hora de incentivar la participación política de los ciudadanos.

\section{La publicidad política en los procesos democráticos}

En América Latina, carente de orden y esperanza en su vida diaria, un presidente puede mover emocionalmente a los ciudadanos con discursos motivacionales y propuestas atractivas desde lo comunicativo, incluyendo más seguridad, guerra a la corrupción y la cero tolerancia con la politiquería o con las malas prácticas en el uso de los recursos públicos. Entonces, la comunicación adquiere la característica 
de poder ser generador de gobernabilidad, legitimidad y credibilidad pública en las democracias latinoamericanas.

La política a través de los medios de comunicación busca movilizar a los ciudadanos, haciendo uso de los agentes, escenarios y discursos, pero sobre todo, del entretenimiento; a esto se le conoce como "mass mediatización de la política” (Ferry, 1992; Verón, 1992). Actualmente, las campañas políticas no se limitan al proceso electoral. Una vez obtenido el triunfo, el gobernante continúa permanentemente en campaña con la promesa de leyes, acciones y políticas, en lugar de concretarlas. Busca, mantener expectante a la ciudadanía y, de tal manera, aprovechar su esperanza ante la crisis de gobernabilidad y gestión en la que se encuentran en ese momento (Rincón \& Bonilla, 2014).

En los países democráticos se "ha aumentado el uso de la videopolítica, en la que se prefieren las imágenes en demérito de lo argumentativo, y lo emocional sobre lo racional. [En ese sentido] la composición audiovisual domina una importante proporción de la actividad proselitista y llega a incorporar, incluso, elementos de la lógica del espectáculo” (Sádaba, 2003, p. 168). La televisión es el medio que más ha influido en el perfil de los candidatos y en la naturaleza del discurso político, modificando la forma de hacer campañas. De esa manera, se destaca el uso del spotpolítico, como una de las herramientas más importantes de la comunicación política, al transformar a los políticos en actores, crear identidades y favorecer los sistemas de decisión en la generación de una cultura política que incentive la participación política de los ciudadanos (Drew y Weaver, 2006).

Es a través del spot que los candidatos o los partidos políticos comunican, transmiten ideales, propuestas, esto es, convencen a la ciudadanía generando empatía, promoviendo sus creencias, actitudes y conductas para influir en la emisión del voto de los ciudadanos (Kaid, 1981). Los spots son aquellos "mensajes políticos transmitidos por televisión en épocas de campaña, los cuales pueden tener la particularidad de ser convincentes, estructurados por los mismos partidos y no ser televisivos en campaña, eminentemente persuasivos, construidos por 
los propios partidos políticos y no ser interferidos por los medios de comunicación” (Sádaba, 2003, pp. 166-167).

Por consiguiente, se dará a conocer una explicación detallada acerca del papel de la publicidad política en los 4 países pertenecientes a la Alianza del Pacífico, esto con el fin de determinar sus similitudes y diferencias, así como la relación que existe entre gobernabilidad, democracia y comunicación política.

\subsection{Comunicación Política en Perú}

Hablar de Fujimori es mencionar al presidente que más votos ha tenido en la historia de este país, derrotando a un candidato lleno de características positivas y con un gran apoyo económico como lo era Vargas Llosa y cambiando los paradigmas establecidos por la comunicación política (Protzel, 1991, p. 4). Lo que demuestra lo contradictorio que puede ser el ideario político de los ciudadanos en Perú, que prefirió a alguien más cercano a lo que el votante promedio es, alguien que busca trabajar y estar cercano al pueblo. Otro ejemplo es el caso de Ollanta Humala, que en 2011 hace uso de este tipo de publicidad emotiva, aprovechando ahora el uso de nuevas herramientas, como lo son los medios digitales. Esta campaña muestra a un candidato humano, de familia, haciendo uso de recursos como la música para llegar a sus votantes, promoviendo la igualdad, la cual era notable en sus spots y que, además recurría a su familia. De esta manera, se continua la línea de búsqueda de la emotividad y la empatía con el electorado, es decir el objetivo de estas campañas es que, de alguna manera, el ciudadano se sienta en igualdad y cercanía con el candidato (Matute, 2011).

\subsection{Comunicación Política en Colombia}

En el caso colombiano, Rincón (2004) considera que más que un pacto político democrático entre el gobierno y los ciudadanos, lo que aconteció en el país fue, sobre todo, un pacto comunicativo. Muestra de ello es que en los spots no se hace referencia al Gobierno, sino al presidente como una promesa política. Además de enfatizar 
su discurso de la lucha contra la corrupción, donde se hace uso más de una identidad individual, las características del presidente son las que dirigen la campaña y no el partido ni los argumentos (2004, p. 6).

En ese sentido, se pueden tomar de ejemplo las elecciones para los periodos presidenciales 2010-2014 y 2014-2018 en las que ganó Juan Manuel Santos Calderón. Este candidato se basó en elementos como la Paz, la equidad y la Educación, y el éxito de su reelección se debió básicamente a que hizo uso del recurso de la búsqueda de la paz en el país a través del proceso de paz que inició con las FARC y que se analiza también en el ELN. En los spots políticos se pueden encontrar elementos diversos, como música especialmente elaborada para la campaña, mucho color reflejando la diversidad del contexto colombiano, así como también el hecho de la generación de slogans que motivaban a la identidad colectiva como "vamos para adelante" "vamos para arriba", que incentivaron más la emotividad de los votantes y no tanto la transmisión de elementos sólidos que permitieran hacer una reflexión crítica a la hora de emitir un voto.

\subsection{Comunicación Política en Chile}

La publicidad política en Chile ha sufrido cambios estructurales. En la época del General Pinochet no existía pluralidad en los medios de comunicación, pues solo se buscaba incentivar el cuidado de la imagen gubernamental, y no se permitía ninguna crítica al Gobierno (Ortega, 1999). Con el plebiscito de 1988 surge realmente la publicidad política como tal, al establecerse la Ley orgánica Constitucional sobre votaciones populares y escrutinios en el que se regula que durante el plebiscito se disponen de 30 minutos para publicidad: 15 minutos para el gobierno en turno y los otros 15 minutos para todos aquellos partidos de ideas opuestas al régimen (Aceves, 2000). Autores como Valenzuela (2014) señalan que en Chile la publicidad política hace uso de elementos del marketing, teniendo como objetivo comercializar al candidato. 


\subsection{Publicidad Política en México}

En México, los inicios del uso de la mercadotecnia y la publicidad tienen sus orígenes en 1988 con la difusión de algunas encuestas. Pero solo hasta 1994 se puede hablar del uso de la publicidad política con estrategias de campañas electoral, siendo el ejemplo de esta la campaña electoral de Ernesto Zedillo, representante del Partido Revolucionario Institucional (Aceves, 2000). Esto como resultado de las reformas electorales de 1993, en la que se hace referencia a los lineamientos en cuanto al tiempo en radio y televisión para hacer campaña política. En 1997, los resultados ponen en evidencia el papel trascendental de la publicidad para incentivar la participación política y pone en discusión la necesaria reglamentación. El elector lejos de votar por un candidato con pleno conocimiento de propuestas y programas a desarrollar, vota por un objeto, con lo que se puede concluir que a mayor presupuesto de campaña, más votos tendrá el candidato (Juárez, 2009).

De acuerdo a la encuesta de campañas políticas realizadas por Parametría (2015), se encuentra que el 66\% de los mexicanos no les gustan los spots políticos y el 64\% afirmó que no influyeron en su decisión del voto. Sin embargo, se sigue haciendo uso de estos para llegar a toda la población y hacer de alguna manera entendible la política.

Ante lo mostrado en los párrafos anteriores, el imperativo categórico de marketing político -surgido a la postre de las experiencias democrático-electorales en América Latina- supone una "americanización de la política” (Aceves, 2009, p. 37) que, en términos negativos, advierte una "reducción" de lo democrático y de lo político a simplismos publicitarios. No obstante, cuando la americanización sugiere un cambio en el proceso político y en el desarrollo del mismo, la mercadotecnia deberá asirse al concepto del arte, pues en su sentido político se establece como baluarte de la libertad (Juanes, 2010).

La creciente "americanización" es un fenómeno que va en ascenso en América Latina. Se caracteriza por la personalización de la política, ventaja del candidato sobre el partido y utilización de la televisión y campañas mediáticas para descalificar a la oposición (Zovatto, 2007). 
Es necesario que tanto los académicos latinoamericanos como los habitantes de la región piensen en que el entretenimiento y la diversión en el "juego de la democracia" sumirán en el olvido los dolores impuestos tanto por la sociedad misma como por la dinámica político-estatal; de tal manera que forjar mecanismos de apertura educativa y tecnológica en la región, como lo sugiere la Alianza Pacífico, estimulará el pensamiento que aleje la obcecación de aquellos totalitarismos que convierte al marketing político en una "barbarie estilizada" (Juanes, 2010, p. 122).

\section{Conclusiones}

La participación política favorece la consolidación de las democracias, y el papel del Estado es primordial para lograr que se geste una relación sana entre los gobernantes y los gobernados. Generar mecanismos de participación política sólidos, basados en el marco regulatorio de cada país, provocará la institucionalización que propicie la consolidación democrática en sentido amplio.

En el marco del acuerdo regional Alianza Pacífico, podríamos decir que este se convierte en un sistema político globalizado, que tiene como finalidad buscar los puntos en común entre los países miembros para favorecer el crecimiento regional sin desigualdades. La premisa ahora es seguir trabajando en la lucha de esa igualdad, ya que en la búsqueda de una economía global, los problemas económicos, políticos y sociales se tornarán cada vez mayores y plurales. La solución a esto es encontrar la legitimidad interna de cada país y esta se logra a través del fomento de la participación política de sus ciudadanos.

Los Estados necesitan instituciones fuertes y con la apertura necesaria para que el ciudadano se sienta cercano e involucrado en la toma de decisiones y diseño de políticas públicas que repercuten en la vida diaria, fortaleciendo así la gestión en cada país, consolidando al sistema político y favoreciendo el crecimiento y desarrollo económico.

Si bien, ya se indicó la importancia de la participación de los ciudadanos para la consolidación de la democracia, se puede decir que en 
los países miembros de la Alianza han estado emprendiendo acciones desde el marco regulatorio que favorezcan esa movilización. Todavía hay cosas por mejorar, como hacer entendibles los mecanismos a los ciudadanos, la transmisión de la información y el seguimiento que son las acciones a seguir tratando en futuras investigaciones.

En ese sentido, el papel de la publicidad tendrá que ser modificado. Las campañas políticas en los países miembros se han limitado a ser solo motivos de diversión y conocimiento de características ajenas a las capacidades políticas o propuestas de fondo. Lejos ha quedado el papel real de formar a los ciudadanos necesarios para una democracia sana y consolidada, pues se les siguen proveyendo desinformación necesaria para sistemas políticos en los que no se busca realmente el desarrollo de su sociedad.

\section{Referencias}

Abundis, F. (2007). Los medios de comunicación en México. AMMAI, $13,42-45$.

Aceves González, F. (2000). La investigación académica sobre el papel de los medios de comunicación en los procesos electorales en México. Comunicación y Sociedad, 37, 11-36.

Adorno, T. (2007). Dialéctica de la ilustración. Madrid: Akal.

Alvarez, L. (1989). La mediatización de la política. Reflexiones sobre el ágora electrónica, Cuadernos del CLAEH, 49, Montevideo: CLAEH

Bartra, R. (2013). Territorios de terror y la otredad. México: FCE.

Bobbio, N. (1987). La Democracia de los Modernos: comparacón con las de los antiguos y con la de los postreros. Madrid: Trotta.

Bovero, M. (2002). Una gramática de la democracia. Madrid: Trotta.

Bustamante, G., \& Morandé, J. (2007). Nuevas Estrategias de Cooperación en América Latina. Creación de redes solidarias a partir de la sociedad civil. El caso Coaniquem. Estudios Internacionales (136), 107-138.

Castells, M.(1997). Política informacional y crisis de la democracia. En M. Castells, (Ed). La era de la información. Madrid, Alianza.

CEP (2014). Estudio Nacional de Opinión Pública. Chile: Centro de Estudios Públicos. 
Chilena, M. (25 de abril de 2015). Biblioteca Nacional Digital. Recuperado de wwww.memoriachilena.cl/602/w3-article-3382.html

Dahl, R. (1992). La democracia y sus críticos. Buenos Aires, Agentina: Paidós

ENCUP. (2012). Encuesta Nacional sobre Cultura Política y Prácticas ciudadanas. México: Secretaría de Gobernación.

Encuesta de Cultura Política (2013). Departamento Administrativo Nacional de Estadística. Gobierno de Colombia: Colombia.

Fromm, E (1982). El miedo a la libertad. Barcelona: Paidós

Fuentes, C., \& Villar, A. (2005). Voto Ciudadano: Debate sobre la inscripción electoral. Nueva Serie.

Galeano, E. (2015). Las venas abiertas de América Latina. México, D.F: Siglo XXI.

Gómez, T. T., \& Aguilar, L. (2013). La cultura Política de los jóvenes en México. México: Colegio de México.

Grindle, M. (2009). La brecha de la implementación. En Freddy Mariñez y Vidal Garza (Eds.). Política pública y democracia en América Latina. Del análisis a la implementación (pp. 33-51). Instituto Tecnológico de Estudios Superiores de Monterrey: México.

Habermas, J. (2014). Teoría de la acción comunicativa. Madrid: Trotta.

Hardt, M., \& Negri, A. (2005). Imperio. Barcelona: Paidós.

Horkheimer, M. (2008). Teoría crítica. Buenos Aires: Amorrortu.

IFE. (2012). Procesos electorales 2012. México: Instituto Federal Electoral.

INEI (2010). Participación Ciudadana. Compendio Estadístico, Perú. Instituto Nacional de estadística e informática: Perú.

Juanes, J. (2010). T.W Adorno. Individuo autónomo-arte disonante. México, DF: Magneta.

Kaid, L. L. (1981). Political Advertising. En D. Nimmo \& K. R. Sanders (Eds), Handbook of Political Communications (pp. 249-271). Beverly Hills, CA: Sage.

Kymlicka, W., \& Norman, W. (1997). El retorno del ciudadano. Una revisión de la producción reciente en teoría de la ciudadanía. Ágora núm. 7, 5-42.

Ley Concejal joven. Diario Oficial del Perú. Lima Perú. 10 de agosto de 2006. Ley No. 27783. Diario oficial de la República de Chile. Santiago de Chile. 16 de octubre de 2001.

Ley 134. Diario Oficial 41.373. Bogotá, Colombia. 31 de mayo de 1994. Levinas, E. (2012). Totalidad e Infinito. Salamanca: Ediciones Sígueme. 
Marx, C. (1991). El Capital. Crítica de la economía politica. México: Fondo de Cultra Económica.

Melucci, A. (2010). Acción colectiva, vida cotidiana y democracia. México: El Colegio de México, Centro de Estudios Sociológicos.

Moreno, C. (2012). Los efectos de las campañas electoralessobre el sentimiento de eficacia política. Revista Española de Ciencia Política, 55-74.

Mouffe, C. (2011). En torno a lo político. Buenos Aires: Fondo de Cultura Económica.

Osorio, J. (2014). El Estado en el centro de la mundialización. La sociedad civily el asunto del poder. México: FCE.

Parametría (2015). Elecciones 2015 y la seguridad. Investigación estratégica y análisis de opinión y mercado: México.

Piketty, T. (2014). El capital en el siglo XXI. México: FCE.

Risse-Kappen, T. (1996). Exploring the Nature of the Beast: International Relations Theory and Comparative Policy Analysis Meet the European Union, Journal of CommonMarket Studies, 34 (1), 53-80.

Rincón, O. (2002). La televización de la política: Uribe: ¿una producción de la realidad o una historia deficción? Revista Foro 45, 38-49

Reyes, A., Romero, F., De Onís, F., Baeza, R., \& Arciniegas, G. (1977). Los clásico. Historiadores de las Indias. México: Cumbre.

Sádaba, T (2003). Los anuncios de los partidos en televisión. El caso de España (1993-2000). En S. Berrocal, S. (Ed.). Comunicación política en televisión y nuevos medios. Barcelona: Editorial Ariel.

Schumpeter, J. (1950). Capitalismo, Socialismo y Democracia. London: Routledge. Secretaría General de Gobierno, G. d. (2011). Politica para la participación ciudadana en el marco de la corresponsabilidad. Chile: Ministrio Secretaría General de Gobierno. Recuperado de www.msgg.gob.cl/wp-content/ uploads/2011/11.politicaparticipacion1.pdf

Secretaría General de Gobierno, G. D. (2015). Orientaciones para la implementación del instructivo presidencial de participación ciudadana. Santiago: División de organizaciones sociales. Gobierno de Chile.

Sharoni, S. (2012). E-citizenship: Trust in Goverment, Political Efficars and Political Participation in the Internet Era. Electronic Media and Politics, 119-135.

Tourine, A. (1995). ¿Qué es la democracia? Buenos Aires: Fondo de Cultura Económica. 
106 / Alma R. Saldierna Salas, Felipe de Jesús Marañón Lazcano, José

FREDMAN MENDOZa IBARRA

UNESCO. (1994). 44 reunión de la Conferencia Internacional de Educación. GINEBRA: UNESCO.

Velázquez F. \& González, E. (2003). ¿Qué ha pasado con Colombia? Colombia: Fundación Corona.

Zarzurri, R., \& Ganter, R. (2002). Memorias, Cultura y nuevas narrativas juveniles. Santiago: Centro de Estudios socio-culturales.

Ziccardi, A. (2009). Participación ciudadana y políticas sociales en el ámbito local. Instituto de investigaciones sociales. México: UNAM. Recuperado de http:// www.iis.unam.mx/pub_elect/zic/, el 17 de mayo de 2009]. 